\title{
Pulmonary Oxidative Status in Norma and Pathologies on the Basis of Analysis of Exhaled Breath Condensate
}

\author{
Eldar Kh. Anaev ${ }^{1}$, Vladimir V. Apyari ${ }^{2}$, Elena A. Puganova ${ }^{2}$, Anastasiya V. Borisova ${ }^{2}$, \\ Stanislava G. Dmitriyenko², Elena E. Karyakina', Mikhail Yu. Vagin ${ }^{2}$, Yurii A. Zolotov², \\ Alexander G. Chuchalin ${ }^{1}$, Arkady A. Karyakin ${ }^{2 *}$
}

\author{
${ }^{1}$ Research Institute of Pulmonology, Moscow, Russia; \\ *Corresponding author \\ Prof. Arkady A. Karyakin \\ Chemistry faculty \\ M.V. Lomonosov Moscow State University \\ Moscow, Russia. \\ Email: aak@analyt.chem.msu.ru
}

${ }^{2}$ Chemistry faculty of M.V. Lomonosov Moscow State University, Moscow, Russia

Received: 21 June 2010; | Revised: 1 July 2010; | Accepted: 12 August 2010

\begin{abstract}
On the basis of analysis of the exhaled breath condensate (EBC), which is truly non-invasively collected, we propose to evaluate the pulmonary oxidative status. As known, both peroxides, primarily hydrogen peroxide $\left(\mathrm{H}_{2} \mathrm{O}_{2}\right)$, and nitrite ions $\left(\mathrm{NO}_{2}{ }^{-}\right)$present in EBC. However, where as peroxides serve as strongest oxidants, nitrite in the same medium due to its electrochemical potential can only be a reductant. We have shown, that $\mathrm{H}_{2} \mathrm{O}_{2}$ concentration in EBC being at micromolar level for healthy human is increased in case of inflammatory pathologies (asthma, pneumonia, bronchiectases). Moreover, monitoring $\mathrm{H}_{2} \mathrm{O}_{2}$ in $\mathrm{EBC}$ one can evaluate the degree of inflammation (exacerbation vs remission) and even improve the personified therapy. On the contrary, nitrite concentration in case of similar inflammatory deceases is decreased. A simultaneous increase of oxidant $\left(\mathrm{H}_{2} \mathrm{O}_{2}\right)$ and a decrease of reductant $\left(\mathrm{NO}_{2}{ }^{-}\right)$concentrations in EBC point to a significant pulmonary oxidative stress accompanying inflammatory pathologies.
\end{abstract}

Keywords: Exhaled breath condensate; hydrogen peroxide; nitrite; inflammation; oxidative stress.

\section{Introduction}

Non-invasive diagnostics attracts nowadays a growing interest. However, there are only a few approaches allowing truly non-invasive quantitative evaluation of key blood metabolites. Among them the minimal traumatic for patients provides the collection of exhaled breath condensate $(\mathrm{EBC})$. Appearance in clinical practice of commercial EBC collectors has led to standardization of this method.

Among the great advantages of EBC is a possibility to deliver a kind of portrait of metabolites. Indeed, due to a minor presence of proteins, the biocatalytic activity in EBC is 
negligibly low. Hence, even the ratio of redox metabolites reminds it in vivo.

Hydrogen peroxide $\left(\mathrm{H}_{2} \mathrm{O}_{2}\right)$ is known to be the strongest oxidant in organisms, characterized in physiological solutions by the highest oxidative potential, which is even higher than that of superoxide radical $\left(\mathrm{O}_{2}^{-}\right)$[1]. In contrast to the superoxide, $\mathrm{H}_{2} \mathrm{O}_{2}$ is stable in aqueous solutions, and hence can be considered as a valuable marker for oxidative stress.

Existence of hydrogen peroxide in exhaled breath condensate has already been reported by a number of authors [2-4]. The main problem with the existent data, however, is a remarkable variation of $\mathrm{H}_{2} \mathrm{O}_{2}$ concentrations reported even for healthy human. The lowest reported values are less than hundreds of nano-moles per liter [5], where as some authors claim several micro moles per liter content of hydrogen peroxide in EBC [6, 7]. As seen, the amplitude is almost two orders of magnitude.

Another problem with the reports on hydrogen peroxide concentration in EBC is the generally accepted it's increase in case of nearly all lung diseases [8]. However, where as for inflammatory diseases (asthma, pneumonia etc.) the increase of $\mathrm{H}_{2} \mathrm{O}_{2}$ in EBC [9-11] is expected due to oxidative radical formation as organism response, the pathologies like chronic obstructive pulmonary disease (COPD) are not directly accomplished with the free radical formation mechanism. Nevertheless, even for COPD the remarkable raise in hydrogen peroxide concentration is reported $[12,13]$.

We already reported on Prussian Blue as the most advantageous hydrogen peroxide transducer [14-16]. Comparing with the most widely used platinum, Prussian Blue modified electrodes are: (i) three orders of magnitude more active in $\mathrm{H}_{2} \mathrm{O}_{2}$ reduction and oxidation in neutral media, and (ii) three orders of magnitude more selective for hydrogen peroxide reduction in the presence of oxygen [17]. The attractive performance characteristics of the electrochemically deposited Prussian Blue allowed to denote it as artificial enzyme peroxidase $[15,16]$. Moreover, on the basis of nano-structured Prussian Blue (its nanoelectrode arrays) the electrochemical sensor with the record performance characteristics has been elaborated [18, 19]. Hence, it was highly attractive to apply the advanced sensor for hydrogen peroxide to monitor $\mathrm{H}_{2} \mathrm{O}_{2}$ in $\mathrm{EBC}$.

Except for $\mathrm{H}_{2} \mathrm{O}_{2}$, a number of metabolites were found in EBC. Our interest attracted nitrite $\left(\mathrm{NO}_{2}{ }^{-}\right)$, an ion closely chemically related to nitric oxide (NO), which is known to have a great biological importance [20]. Nitrite can serve as both oxidant and reductant and, hence, can also be considered as a marker for oxidative stress. Nitrite found to be at a level of 0.33-3.3 micromoles per liter of EBC in normal non-smokers [21, 22]. In literature the concentration of nitrite in EBC is increased in case of any pulmonary disease [23-25].

We, however, note that a potential of $\left(\mathrm{NO}_{3}{ }^{-}\right.$ $/ \mathrm{NO}_{2}{ }^{-}$) redox couple is almost equal to normal hydrogen potential $(0.01 \mathrm{~V}, \mathrm{NHE})$, which is dramatically lower compared to redox potential of $\left(\mathrm{H}_{2} \mathrm{O}_{2} / \mathrm{H}_{2} \mathrm{O}\right)$ reaction (1.77 $\mathrm{V}$, NHE) [26]. For comparison, the voltage required for water decomposition into hydrogen and oxygen is just $1.23 \mathrm{~V}$. Hence, nitrite versus $\mathrm{H}_{2} \mathrm{O}_{2}$ as metabolite of oxidative stress can be considered only as a reductant, rather than an oxidant. This makes doubtful the reported increase of both $\mathrm{H}_{2} \mathrm{O}_{2}$ and $\mathrm{NO}_{2}{ }^{-}$in EBC in case of inflammatory diseases.

In the present work we combined efforts of clinicians and analytical chemists to evaluate pulmonary oxidative status on the basis of EBC analysis. We've proven that hydrogen peroxide concentration in EBC of healthy human exists at a level of micro-moles per liter. Low-inflammatory pathologies (COPD) cause a small increase of $\mathrm{H}_{2} \mathrm{O}_{2}$ content in EBC. On the contrary, the main inflammatory diseases (asthma, pneumonia etc.) are accomplished by a significant (up to several times) increase of hydrogen peroxide content in EBC. A simultaneous increase of $\mathrm{H}_{2} \mathrm{O}_{2}$ and decrease of $\mathrm{NO}_{2}^{-}$content in $\mathrm{EBC}$ points to a significant pulmonary oxidative stress upon inflammatory pathologies.

\section{Experimental}

\subsection{Subjects}

Four groups of in-patients $(n=151)$ were included in the present study: COPD patients with stage II-III disease $(n=70)$; patients with moderateto-severe asthma $(n=44)$; patients with moderate 
community-acquired pneumonia $(n=24) ;$ and patients with bronchiectases $(n=13)$.

The diagnosis of COPD, asthma, pneumonia and bronchiectases were based on the generally accepted (standard) criteria [27-29].

The control group included 74 subjects (age range 24-34 yrs; mean \pm SD $24 \pm 5$ yrs), including 27 healthy smokers without symptoms (St George's questionnaire for symptoms such as cough and sputum production) whose lung function parameters were normal. Atopy and allergies were excluded.

The Ethics Committee of Research Institute of Pulmonology, Moscow, Russia, approved the study protocol, and all subjects gave informed consent before participating.

\subsection{Chemicals}

Experiments were carried out with MilliQ water from a Millipore MilliQ system. All inorganic salts and hydrogen peroxide $(30 \%$ solution) were obtained at the highest purity from Reachim (Moscow, Russia) and used as received.

Horse radish peroxidase (HRP), 2,2'-azinobis(3-ethylbenzthiazoline-6-sulfonic acid) (ABTS), catalase from bovine liver were purchased from Sigma-Aldrich (Steinheim, Germany).

Exhaled breath condensate (EBC) samples were collected using a commercially available condenser ECoScreen ${ }^{\circledR}$ (Erich Jaeger GmbH, Germany) in morning hours. After rinsing their mouths, subjects breathed tidally through a mouthpiece and a two-way nonrebreathing valve, in which inspiratory and expiratory air were separated, and saliva trapped. They were asked to breathe at a normal frequency, wearing a nose clip, for a period of $10 \mathrm{~min}$ to obtain approximately 1.5 $\mathrm{ml}$ condensate. All collected samples were immediately stored at $-70^{\circ} \mathrm{C}$ and kept for less than a week before analysis.

\subsection{Hydrogen peroxide detection}

Hydrogen peroxide concentration in EBC was detected in flow-injection system equipped with Prussian Blue based sensors. The flow injection system consisted of a Cole Parmer (Vernon Hills, IL) peristaltic pump (7519-10), homemade flowthrough wall-jet cell with $0.5-\mathrm{mm}$ nozzle positioned at $1 \div 2$-mm distance from the surface of disk electrode, $(\mathrm{Ag}|\mathrm{AgCl}| 1 \mathrm{M} \mathrm{KCl})$ reference, homemade injector, and PalmSens potentiostat (Palm Instruments BV, Netherlands) interfaced to an IBM PC. Flow rates used were in the range $0.5 \div 1 \mathrm{~mL} \mathrm{~min}^{-1}$. In FIA experiments, the peak current values were taken for data treatment, sample volume was $50 \mu \mathrm{l}$, and working electrode potentials were $0.00 \div 0.05 \mathrm{~V}$, allowing hydrogen peroxide reduction on Prussian Blue-modified electrodes. Carrier solution was $0.05 \mathrm{M}$ phosphate buffer ( $\mathrm{pH}$ 6.0) containing $0.1 \mathrm{M} \mathrm{KCl}$. EBC prior to injection was diluted 3 times with the carrier.

Prussian Blue based sensors for hydrogen peroxide were elaborated on the basis of screen printed three-electrode chips with carbon both working and counter electrodes, and $\mathrm{Ag} \mid \mathrm{AgCl}$ reference. Prussian Blue was deposited in cyclic voltammetric conditions with switching potentials of $0.3 \div 0.4 \mathrm{~V}$ (cathodic) and of $0.7 \div 0.8 \mathrm{~V}$ (anodic) at a sweep rate of $40 \mathrm{mV} \mathrm{s}^{-1}$, or by applying a constant potential of $0.4 \mathrm{~V}$ as described elsewhere [16]. Growing solution contained $4 \mathrm{mM}$ $\mathrm{K}_{3}\left[\mathrm{Fe}(\mathrm{CN})_{6}\right]$ and $4 \mathrm{mM} \mathrm{FeCl}_{3}$. A solution of 0.1 $\mathrm{M} \mathrm{HCl}$ and $0.1 \mathrm{M} \mathrm{KCl}$ was used as supporting electrolyte. After deposition, Prussian Blue films were electrochemically activated in the same supporting electrolyte by cycling in the range $-0.05 \div 0.35 \mathrm{~V}$ at a rate of $40 \mathrm{mV} \mathrm{s}^{-1}$ until a stable voltammogram was obtained. Then the electrodes were heated at $100^{\circ} \mathrm{C}$ for 1 hour.

Spectrophotometric hydrogen peroxide detection was carried out using LKB-Ultraspec VII (Bromma, Sweden) spectrophotometer. Concentration of peroxidase and ABTS (extinction coefficient ( $\varepsilon$ ) of $35 \mathrm{mmol} \mathrm{L}^{-1} \mathrm{~cm}^{-1}$ at $405 \mathrm{~nm})$ in phosphate buffer $(\mathrm{pH} 5.5)$ was $5 \cdot 10^{-9}$ mol $\mathrm{L}^{-1}$ and $5 \cdot 10^{-4} \mathrm{~mol} \mathrm{~L}^{-1}$, respectively. Calibration was made considering initial rates of peroxidase-catalyzed ABTS oxidation by hydrogen peroxide at certain concentrations of the latter. Peroxidase concentration was independently controlled at $403 \mathrm{~nm}\left(\varepsilon=1.05 \cdot 105 \mathrm{~mol} \mathrm{~L}^{-1} \mathrm{~cm}^{-1}\right)$.

\subsection{Nitrite detection}

The detection principle was the diazotization of the end toluidine groups of polyurethane foam by nitrite ions in acidic medium with subsequent 
coupling with 3-hydroxy-7,8-benzo-1,2,3,4tetrahydroquinoline [30]. The latter was synthesized as follows. 1-Naftilamine $(42.9 \mathrm{~g}, 0.3$ $\mathrm{mol})$ and epichlorhydrin $(27.9 \mathrm{~g}, 0.3 \mathrm{~mol})$ in $40 \mathrm{ml}$ of 1,2-dichlorobenzene were shaken at $160{ }^{\circ} \mathrm{C}$ for 7 hours. The precipitate was washed with $\mathrm{PhCl}$ and hexane subsequently (10 $\mathrm{ml}$ of each). Then the product was suspended in $150 \mathrm{ml}$ of $25 \%$ aqueous $\mathrm{NH}_{3}$ and washed with water to neutral $\mathrm{pH}$. The yield of the final product was $60 \%$.

The product of diazo coupling with intensive orange color was monitored at $470 \mathrm{~nm}$ with the diffusion reflection spectrometer ("Spectrotron", Chimautomatika, Russia). Polyurethane foam was purchased from "Radical" (Kiev, Ukraine).

Nitrite detection in EBC was made as follows. One milliliter of EBC was mixed with $1 \mathrm{ml}$ of $5 \mathrm{M}$ $\mathrm{HCl}$ and $3 \mathrm{ml}$ of water. Afterwards a tablet of polyurethane foam was immersed in this solution and shook for $30 \mathrm{~min}$. The tablet of diazotized polyurethane foam was dried with blotting paper and then immersed in aqueous solution of $100 \mu \mathrm{g}$ 3-hydroxy-7,8-benzo-1,2,3,4-tetrahydroquinoline in $5 \mathrm{~mL}$ of $0.2 \mathrm{~mol} \mathrm{~L}^{-1} \mathrm{Na}_{2} \mathrm{CO}_{3}$. After $30 \mathrm{~min}$ of shaking the tablet was washed and the diffusion reflection spectra were recorded. Nitrite concentration in EBC was estimated from calibration graph.

\subsection{Statistical analysis}

Data are presented as mean \pm SD for not normally distributed data. Data for all groups were analyzed by the Kruskall-Wallis test and differences between individual variables from two groups were analyzed by the Mann-Whitney Utest. Correlations between variables were sought using the Spearman rank correlation test. A pvalue $<0.05$ was considered significant.

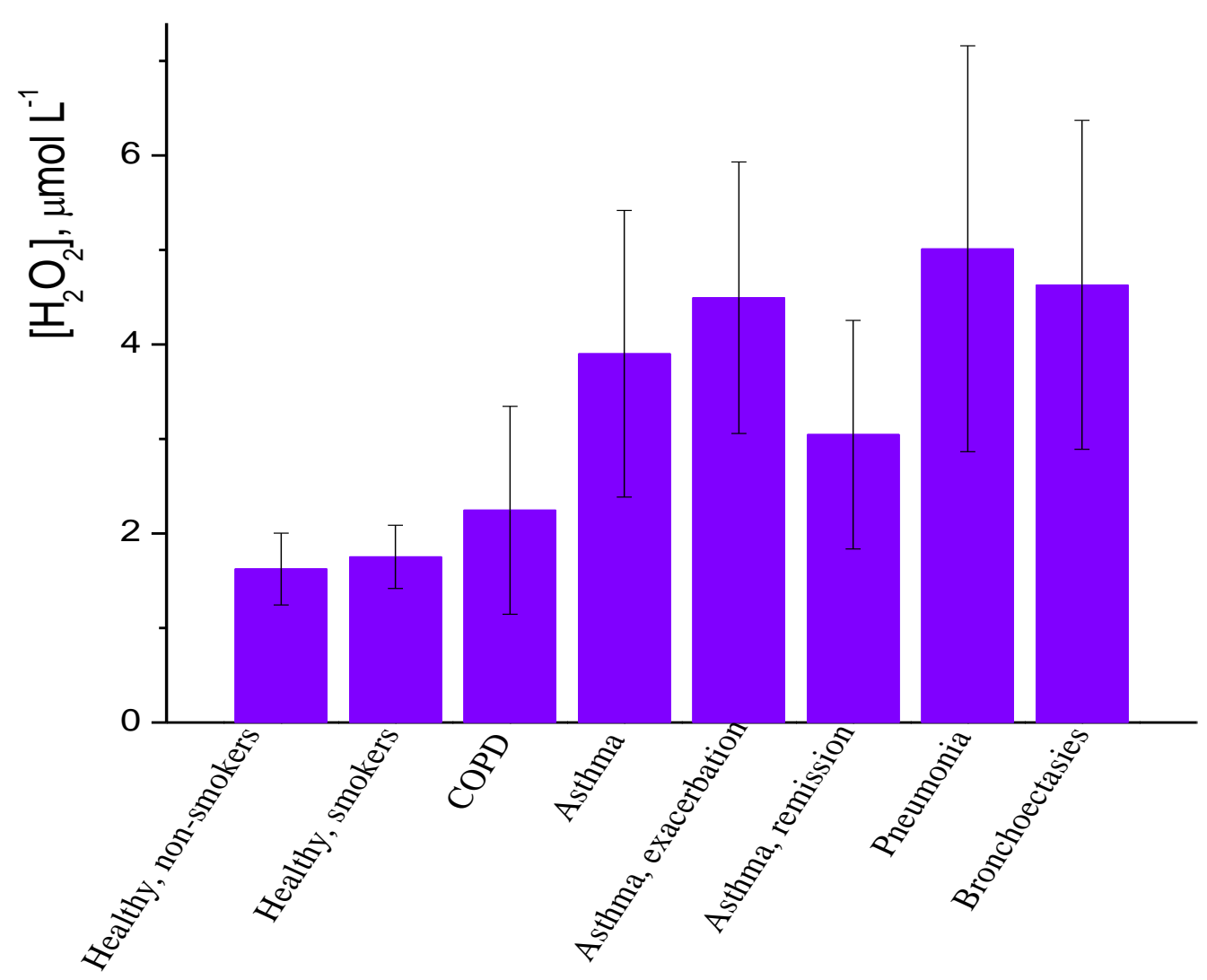

Figure 1. Concentration of hydrogen peroxide $\left(\mathrm{H}_{2} \mathrm{O}_{2}\right)$ in $\mathrm{EBC}$ of healthy people and patients with difference pulmonary deceases. 


\section{Results and discussion}

Hydrogen peroxide $\left(\mathrm{H}_{2} \mathrm{O}_{2}\right)$ is already well known as a marker for different pulmonary pathologies. Accordingly, exhaled breath condensate from different groups of pulmonary patients as well as for healthy humans was first analyzed concerning the presence of hydrogen peroxide. Considering huge variation of the reported concentrations of $\mathrm{H}_{2} \mathrm{O}_{2}$ in $\mathrm{EBC}$ (the amplitude is almost two orders of magnitude), we decided first to determine its true level.

As seen in figure 1, the flow-injection (FIA) system equipped with Prussian Blue based hydrogen peroxide sensor responds to EBC as to $\mathrm{H}_{2} \mathrm{O}_{2}$ solutions of micro-Molar concentrations. As published elsewhere, FIA systems equipped with Prussian Blue based sensors usually display the lower limit of the calibration range below 0.1 $\mu \mathrm{mol} / \mathrm{L}$ [15-19]. To confirm, that the response of FIA system was indeed to hydrogen peroxide, the enzyme catalase (which catalyses dismutation of hydrogen peroxide) in concentration of $5 \mu \mathrm{g}$ per $\mathrm{ml}$ was added to EBC. After treatment with catalase the response of FIA system to EBC was decreased by $40-60 \%$. Hence, the main part of the FIA system response is indeed generated by free hydrogen peroxide in EBC. The fact, that treatment with catalase did not cause a complete disappearance of the signal in FIA system, can be explained in terms of complex formation between $\mathrm{H}_{2} \mathrm{O}_{2}$ and organic compounds (like urea). Alternatively, Prussian Blue based sensors can respond to organic peroxides present in EBC.

The reference method for hydrogen peroxide detection in EBC was the peroxidase enzyme spectrophotometric test. The reference gave similar results to flow-injection system (data not shown). We note that peroxidase enzymes are not specific just to hydrogen peroxide, and catalyze reduction of some organic peroxides as well. Hence, from both electrochemical and spectrophotometric investigations we cannot exclude peroxides presented in EBC in form of organic peroxides. We were unable to find analytical tools to discriminate hydrogen peroxide from organic peroxides in EBC and thus refer to total peroxide content as to hydrogen peroxide concentration.
From this part we conclude, that EBC collected with EcoScreen contains $\mathrm{H}_{2} \mathrm{O}_{2}$ at microMolar level.

We determined hydrogen peroxide in EBC of healthy human and of different groups of pulmonary patients. As seen in fig. 1, hydrogen peroxide concentration in EBC of healthy human is at a level of $1.5 \mu \mathrm{mol} \mathrm{L} \mathrm{L}^{-1}$. Smokers have a general tendency for increase of $\mathrm{H}_{2} \mathrm{O}_{2}$ content in their $\mathrm{EBC}$, but the difference with non-smokers in not valuable.

All pulmonary patients are characterized by increased $\mathrm{H}_{2} \mathrm{O}_{2}$ concentration in $\mathrm{EBC}$ (fig. 1). However, for low-inflammatory disease like COPD the increase of $\mathrm{H}_{2} \mathrm{O}_{2}$ content is not valuable. On the contrary, inflammatory pathologies (asthma, pneumonia, bronchiectases) cause the significant increase of $\mathrm{H}_{2} \mathrm{O}_{2}$ concentration in EBC (fig. 1). In certain cases the increase of $\mathrm{H}_{2} \mathrm{O}_{2}$ content versus healthy people encounters 4-5 times. Moreover, detecting hydrogen peroxide in EBC of pulmonary patients it is possible to monitor their therapy. As seen in fig. 1, exacerbation of asthma and its remission are characterized by statistically different levels of hydrogen peroxide concentration: remission causes the decrease of the latter.

We conclude that inflammatory pathologies cause the significant increase of hydrogen peroxide concentration in EBC pointing to pulmonary oxidative stress. It's hence of great importance to measure a content of reducing marker.

Concentration of nitrite ion $\left(\mathrm{NO}_{2}^{-}\right)$in EBC was found to be at the level of $10 \mu \mathrm{mol} \mathrm{L}^{-1}$ for healthy human (fig. 2). Micro-Molar content of nitrite is in accordance with the determined concentration of hydrogen peroxide in EBC. For low-inflammatory decease like COPD nitrite appears in EBC in quite similar concentrations. Exhaled breath condensate of the patients suffering from asthma contains statistically valuable reduced concentrations of $\mathrm{NO}_{2}^{-}$.

Hence, nitrite content in EBC has an inversed correlation with hydrogen peroxide content: there is no significant difference between healthy human and low-inflammatory patients, where as in cases of inflammatory pathologies nitrite concentration in EBC is significantly decreased. 


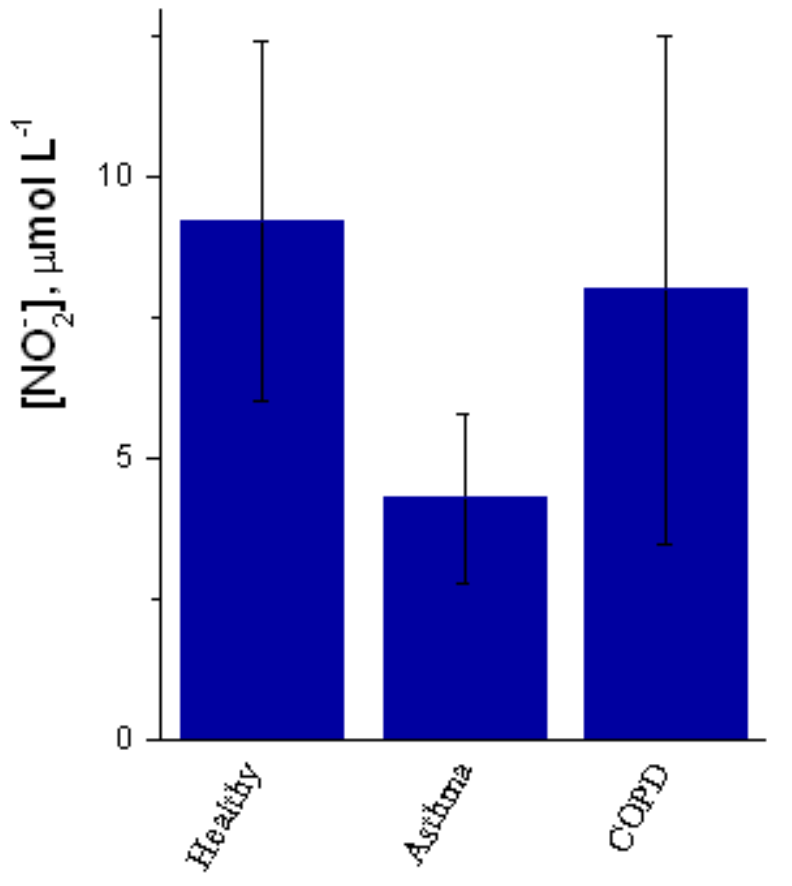

Figure 2. Concentration of nitrite $\left(\mathrm{NO}_{2}^{-}\right)$in $\mathrm{EBC}$ of patients with difference pulmonary deceases

\section{Conclusion}

We conclude, that inflammatory pathologies cause a valuable increase of hydrogen peroxide coupled with a valuable decrease of nitrite concentrations in EBC. A simultaneous increase of oxidant and a decrease of reductant concentrations point to a significant pulmonary oxidative stress accompanying inflammatory pathologies. Curing of such pathologies can be, hence, improved using antioxidants.

\section{Acknowledgements}

The financial support through Russian Foundation for basic research (№03-07-12211), Federal Agency for Science and Innovation (№01200607032), Federal Agency for Education (№ 959-P) and ISTC-3209 are greatly acknowledged.

\section{References}

1. http://www.rsbs.anu.edu.au/O2/O2_1_Redox.h tm

2. Kharitonov, S.A.; Barnes, P.J. Exhaled markers of pulmonary diseases, American Journal of Respiratory and Critical Care Medicine, 2001, 163, 1693-1722.

3. Liu, J.; Thomas, P.S. Exhaled breath condensate as a method of sampling airway nitric oxide and other markers of inflammation, Medical Science Monitor, 2005, 11(8), 53-62.

4. Montuschi, P. Exhaled breath condensate analysis in patients with COPD, Clinica Chimica Acta, 2005, 356(1-2), 22-34.

5. Zappacosta, B.; Persichilli S.; Mormile, F; Minucci, A.; Russo, A.; Giardina, B.; De Sole, P. A fast chemiluminescent method for $\mathrm{H}_{2} \mathrm{O}_{2}$ measurement in exhaled breath condensate, Clinica Chimica Acta, 2001, 310, 187-191.

6. Ferreira, I.M.; Hazari, M.S.; Gutierrez, C.; Zamel, N.; Chapman, K.R. Exhaled nitric oxide and hydrogen peroxide in patients with chronic obstructive pulmonary disease: effects of inhaled beclomethasone, American Journal of Respiratory and Critical Care Medicine, 2001, 164(6), 1012-1015.

7. Sandrini, A.; Ferreira, I.M.; Gutierrez, C.; Jardin, J.R.; Zamel, N.; Chapman, K.R. Effect of montelukast on exhaled nitric oxide and nonvolatile markers of inflammation in mild asthma, Chest, 2003, 124(4), 1334-1340.

8. Wewel, A.R.; Crusius, J.A.M.; Gatzemeier, U.; Heckmayr, M.; Becher, G.; Magnussen, H.; Jörres, R.A.; Holz, O. Time course of exhaled hydrogen peroxide and nitric oxide during chemotherapy, European Respiratory Journal, 2006, 27, 1033-1039.

9. Loukides, S.; Bouros, D.; Papatheodorou, G.; Panagou, P.; Siafakas, N. The relationships among hydrogen peroxide in expired breath condensate, airway inflammation, and asthma severity, Chest, 2002, 121(2), 338-346.

10. Antczak, A.; Kurmanowska, Z.; Kasielski, M.; Nowak, D. Inhaled glucocorticosteroids decrease hydrogen peroxide level in expired 
air condensate in asthmatic patients, Respiratory Medicine, 2000, 94, 416-421.

11. Majewska, E.; Kasielski, M.; Luczynski, R; Bartosz, G.; Bialasiewicz, P.; Nowak, D. Elevated exhalation of hydrogen peroxide and thiobarbituric acid reactive substances in patients with community acquired pneumonia, Respiratory Medicine, 2004, 98, 669-676.

12. Dekhuijzen, P.N.; Aben, K.K.; Dekker, I.; Aarts, L.P.; Wielders, P.L.; van Herwaarden, C.L.; Bast, A. Increased exhalation of hydrogen peroxide in patients with stable and unstable chronic obstructive pulmonary disease, American Journal of Respiratory and Critical Care Medicine, 1996, 154, 813-816.

13. Kostikas, K.; Papatheodorou, G.; Psathakis, K.; Panagou, P.; Loukides, S. Oxidative stress in expired breath condensate of patients with COPD, Chest, 2003, 124(4), 1373-1380.

14. Karyakin, A.A.; Gitelmacher, O.V.; Karyakina, E.E. Prussian Blue-Based FirstGeneration Biosensor. A Sensitive Amperometric Electrode for Glucose, Analytical Chemistry, 1995, 67(14), 24192423.

15. Karyakin, A.A.; Karyakina, E.E. Prussian Blue-based 'artificial peroxidase' as a transducer for hydrogen peroxide detection. Application to biosensors, Sensors and Actuators B, 1999, B57, 268-273.

16. Karyakin, A.A.; Karyakina, E.E.; Gorton, L. Amperometric biosensor for glutamate using Prussian Blue-based "artificial peroxldase" as a transducer for hydrogen peroxide, Analytical Chemistry, 2000, 72(7), 1720-1723.

17. Karyakin, A.A. Prussian Blue and its analogues: electrochemistry and analytical applications, Electroanalysis, 2001, 13(10), 813-819.

18. Karyakin, A.A.; Puganova, E.A.; Budashov, I.A.; Kurochkin, I.N.; Karyakina, E.E.; Levchenko, V.A.; Matveyenko, V.N.; Varfolomeyev, S.D. Prussian Blue based nanoelectrode arrays for $\mathrm{H}_{2} \mathrm{O}_{2}$ detection. Analytical Chemistry, 2004, 76 (2), 474-478.

19. Karyakin, A.A.; Puganova, E.A.; Bolshakov, I.A.; Karyakina, E.E. Electrochemical sensor with record performance characteristics.
Angewandte Chemie-International Edition, 2007, 46 (40), 7678-7680.

20. http://nobelprize.org/nobel_prizes/medicine/la ureates/1998/illpres/

21. Ho, L.P.; Innes, J.A.; Greening, A.P. Nitrite levels in breath condensate of patients with cystic fibrosis is elevated in contrast to exhaled nitric oxide, Thorax, 1998, 53(8), 680684.

22. Latzin, P.; Griese, M. Exhaled hydrogen peroxide, nitrite and nitric oxide in healthy children: decrease of hydrogen peroxide by atmospheric nitric oxide, European Journal of Medical Research, 2002, 7(8), 353-358.

23. Cunningham, S.; McColm, J.R.; Ho, L.P.; Greening, A.P.; Marshall, T.G. Measurement of inflammatory markers in the breath condensate of children with cystic fibrosis, European Respiratory Journal, 2000, 15(5), 955-957.

24. Formanek, W.; Inci, D.; Lauener, R.P.; Wildhaber, J.H.; Frey, U.; Hall, G.L. Elevated nitrite in breath condensates of children with respiratory disease, European Respiratory Journal, 2002, 19(3), 487-491.

25. Hunt, J.; Byrns, R.E.; Ignarro, L.J.; Gaston, B. Condensed expirate nitrite as a home marker for acute asthma, Lancet, 1995, 346, 1235 1236.

26. Dobos, D. Electrochemical data, Akademiai Kiado, Budapest 1975.

27. National Heart, Lung and Blood Institute/World Health Organization. Global strategy for the diagnosis, management, and prevention of chronic obstructive pulmonary disease. NHLBI/WHO Global Initiative for Chronic Obstructive Lung Disease (GOLD) Workshop summary. American Journal of Respiratory and Critical Care Medicine, 2001, 163,1256-1276. For an update of definitions (2004) see http://www.goldcopd.com/. Date last updated: September 2005. Date last accessed: February 28, 2006.

28. Global Initiative for Asthma, Global strategy for asthma management and prevention, National Heart, Lung and Blood Institute, National Institutes of Health, Bethesda, MD (2004) NIH publication 02-3659. see http://www.ginasthma.org/.

C 2010 by NWPII. All rights reserved. 
29. Woodhead, M.; Blasi, F.; Ewig, S.; Huchon, G.; Leven, M.; Ortqvist, A.; Schaberg, T.; Torres, A.; van der Heijden, G.; Verheij, T. J. M. Guidelines for the management of adult lower respiratory tract infections, European Respiratory Journal, 2005, 26, 1138-1180.

30. Dmitrienko, S.G.; Apiari, V.V.; Sviridova, O.A.; Badakova, S.A.; Zolotov Yu.A. The use of diazotization and azocoupling reactions with polyurethane for detection of nitrite-ions with diffuse reflectance spaectroscopy and colorimetry. Vestnik of Moscow University, ser. 2 Chemistry, 2004, 45(2), 131-138. 